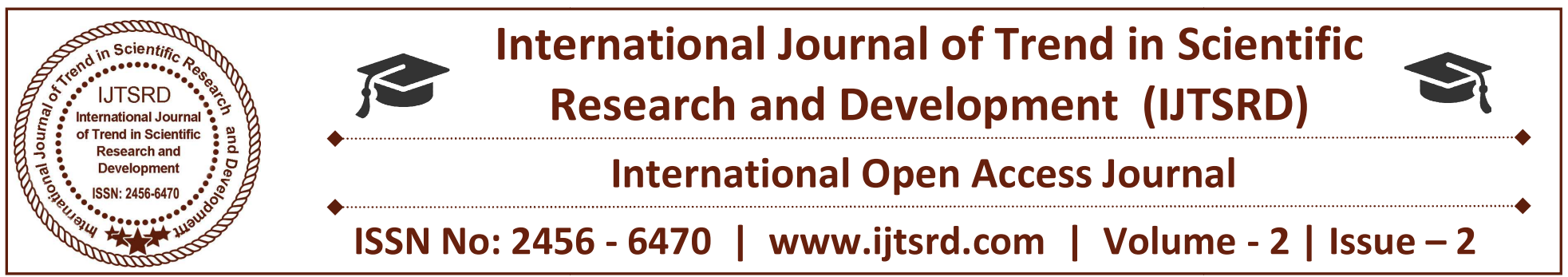

\title{
A Review on Homoeopathic Medicines in Diabetes Mellitus
}

\author{
Dr. Siva Rami Reddy E \\ Research Scholar, Faculty of Homoeopathy, \\ Tantia University, Sri Ganganagar, Rajasthan, India
}

\begin{abstract}
Diabetes Mellitus cases are increasing day to day life throughout the global. It is major medical problem in developing and developed countries in all over world. According to World Health Organization deficiency of insulin secretion, inadequacy insulin secretion from beta cells of pancreas. In order to manage conservative line of treatment with antidiabetes drugs has been developed, but each medicine has their own side effects. So, natural way with Homoeopathic medicines can be effetely post pone diabetic and its complications. In India, certain herbal medicines like Syzygium cumini, Cephalandra Indica, Abroma Augusta, Gymnema Sylvestre and Momordica Charantia, acids, metals, biochemic and minerals can be manage diabetic mellitus. The present review focused that Homoeopathic Medicines are used in Research with scientific evidences.
\end{abstract}

Keywords: Homoeopathic Medicines, Diabetes Mellitus

\section{INTRODUCTION:}

Diabetes mellitus define as glucose circulates through passage. Diabetes mellitus major health problems in all over world. Its leads death with diabetes complication (macro and micro vascular) [1]. Approximately more than 280 million people diagnosed with diabetes mellitus ( Type II) and diabetes complications and this suffering may increase double by the year 2030 [2].

Diabetes mellitus is endocrine disorder characterized by deficiency secretion of insulin, inadequate

secretion of insulin from beta cells of pancreas in human body. Diabetic Mellitus occurs Genetic, chromosomal abnormalities, obesity, lack of exercise and excessive glucose intake. Irregular hyperglycaemic result formation of micro and macro vascular complications. Microvasucalr complications are diabetic retinopathy, diabetic nephropathy, diabetic neuropathy. In macro vascular complications such as cardiomyopathy includes congenital heart disease and $C$ cerebral vascular disease like haemorrhage, infract and mental confession. One of the most complications of diabetes mellitus is hypoglycaemia. Hyper and hypoglycaemia occur do to pathophysiology of diabetes [3]. Various antidiabetic medications such as Syzygium cumini, Cephalandra Indica, Abroma Augusta, Gymnema Sylvestre and Momordica Charantia, acidum, metals, minerals and biochemic or organotherapic remedies.

In this connection, natural way of managing and treating diabetic mellitus condition with homoeopathic medicines all over the world. Homoeopathic medicines and herbal medicines can be managed diabetes and its complications [4-6]. Which have reached epidemic levels global. According to W.H.O on diabetic mellitus recommended that herbal medicinal plants are free from toxic and side effects [7].

In this context, i have reviewed antidiabetic herbals, acids, metals, minerals and biochemic local available, low cost, more effective in India. Such as Homoeopathic Medicines are Syzygium cumini, Cephalandra Indica, Abroma Augusta, Gymnema 
Sylvestre and Momordica Charantia, acids, metals, minerals and biochemic. These homoeopathic drugs will be safe, economic and human friendly.

\section{Syzygium Cumini:}

India has a very long History of using herbal drugs as the main course therapy for treating a number of Diseases. Herbal drugs therapy is regarded as an important for the treatment of a wide range of disease. However envious improvements have been observed in modern system, but India herbal plant provide a rich source for health care to present different pathological status 5 . Syzygium belongs to family Myrtaceae and is known as a kala jamun. The World Health Organization (1980) has also recommended the evaluation of the effectiveness of plants in conditions where there is lack of safe synthetic drugs $^{6}$.Ancient Greeks were well known to this tree in $500 \mathrm{BC}$. According to the literature, A slow growing species, it can reach heights of up to $30 \mathrm{~m}$ and can live more than 100 years. Its dense foliage provides shade and is grown just for its ornamental value. At the base of the tree, the bark is rough and dark grey, becoming lighter grey and smoother higher up. The wood is water resistant. The leaves which have an aroma similar to turpentine, are pinkish when young, changing to a leathery, glossy dark green with a yellow midrib as they mature. The leaves are used as food for livestock, as they have good nutritional $v^{v a l u e}{ }^{7}$.Syzygium cumini trees start flowering from March to April. The flowers are fragrant and small, about $5 \mathrm{~mm}$ in diameter. The fruits develop by May or June and resemble large berries; the fruit of Syzygium species is described as "drupaceous"[8]. The fruit has a combination of sweet, mildly sour and astringent flavour and tends to colour the tongue purple.

In India the plant is available throughout the plains from the Himalayas to southern India. It is found in Thailand, Philippines, Madagascar and some other countries. The plant has been successfully introduced into many other tropical countries such as the West Indies, East and West Africa and some sub tropical regions including Florida, California, Algeria and Israel [9].

The Syzygium genus is one of the Myrtaceae family geniuses which is native to the tropics, particularly in tropical America and Australia. The genus consists of about 1100 species. Plants of this family are known to be rich in volatile oils that are reported to their use in medicaments. Syzygium jambolanum has synonymously Eugenia jambolana Lam., Myrtus cumini Linn, Syzygium jambolana DC., Syzygium cumini (L) Skeels, Eugenia cumini (Linn.) Druce. A smooth tree of the Myrtaceae family, 4-15 meters in height. Leaves leathery oblong-ovate to elliptical or obviate and 6-12 $\mathrm{cm}$ long, the tip being broad and shortly pointed. The panicles are borne mostly from the branchlets below the leaves, often being axillary or terminal and 4-6 cm long. The flowers are numerous, scent, pink or nearly white, without stalks, and borne in crowed fascicles on the ends of the branchlets. The calyx is funnel shaped, about $4 \mathrm{~mm}$ long and 4 toothed. The petals cohere and fall together as a small disk. The stamens are very numerous and as long as the calyx. Fruit is oval to elliptic; $1.5-3.5$ $\mathrm{cm}$ long, dark purple or nearly black, luscious, fleshy and edible; it contains single large seed [10].

\section{Momordica Charantia:}

Momordica charantia known as palisota reichb. Palisota Reichb commonly known as bitter melon, bitter gourd or gourd, was originated from India and carried to China in the 14th century. It is a tropical and subtropical vine of the family Cucurbitaceae, widely grown in Asia, Africa, and the Caribbean. The fruit juice and/or a leaf tea are employed for diabetes, malaria, colic, sores and wounds, infections, measles, hepatitis, and fevers. Leaves are used for treating catarrh, constipation, dermatitis, diabetes, diarrhoea, eczema, fever, leprosy, malaria, rheumatism, breast cancer, snake bite, anaemia, dysentery, gonorrhoea, measles, rheumatoid arthritis. Bitter melon has been shown to increase the number of beta cells in the pancreas thereby improving the body's ability to produce insulin.

Momordica charantia member of Cucarbitaceae, is a slender, tendril climbing, annual vine. Bitter melon is a common food item of the tropics and is used for the treatment of cancer, diabetes and many ailments [1114]. It is a potent hypoglycemic agent [15-17].

\section{Cephalandra Indica:}

Indian systems of traditional medicines namely Homoepathy, Ayurvedia and Unani nearly about 200 plant species for treatment of various diseases from ancient times [18]. About sixty thousand plant species were used for medicinal purpose worldwide [19, 20]. The World Health Organization (WHO) estimated near about $80 \%$ of world population both in 
developing and developed countries use herbal drugs for various ailments. This plant is one of the tremendous plants of Homoeopathy system and Ayurveda .which is commonly known as kundru.[21,22]. Cephalandra Indica widely used in homoeopathy as a mother tincture for type 2 diabetes mellitus.

It is indicated morose, fretful, disc lined to do any work, gloomy, memory partially gone, over sensitiveness, giddiness worse after urination, burning of eyes, dryness of mouth with great thirst for large quantity of water at a time. Dryness of throat. Loss of appetite, flatulency, profuse urinations, weakness and exhaustion after urination, sugar in the urine, greenish mucous, tinged with blood and pain before and during stool, burring all over the body, weak and intermittent [22].

\section{Abroma Augusta:}

This plant widely used in Homoeopathy System of Medicine as Mother Tincture for indication of diabetes mellitus. It was first prover by Dr. D.N.Ray. This plant family sterculiaceae commonly known as ulatkambal and devils cotton. Abroma Augusta is small tree with velvety branches. It is located in Africa, Asia and Australia. In India mainly in Meghalaya, Assam, Kerala, Arunachal Pradesh, Tripura. This plant $4 \mathrm{~m}$ height and reach up to $8 \mathrm{~m}$. Stems yield a fibre. This plant flowering around from June to November. Plant leaves used for diabetes as well as female complaints also.

This plant clinical indicated for albuminuria, sleeplessness, amenorrhoea, carbuncle, debility, dysmenorrhoea and weakness of brain. Mind is irritable, excitable mood, forgetfulness, depression, morose, anxious, unable to moody. Head is empty feeling, rolling of the head and vertigo, heaviness and discomfort, much giddiness, weakness of vision, puffiness of the lids, heaviness, eyes easily tired, inclination to drop eyes closed, pain and watering of the eyes, sneezing several times, nose watering and dryness with desire to rub, face pale, yellow, wrinkled, old looking, itching eruption on the face with burning sensation, furuncles of the face, dry, burring throat, painful, difficulty in swallowing solids but drinking relieves throat symptom temporarily [23].Stomach hungry feeling with faint feeling, desire for all kinds of foods, a feeling of emptiness in the stomach.

\section{Gymnema Sylvestre:}

This plant belongs to asclepiadaceae. Gymnema Sylvestre slow growing, medical plant in peninsular and central in India. It is more in Australia, Africa and India. In India more in Kerala, Andhra Pradesh, Tripura and Arunachal Pradesh. This plant consistence of anthraquinones, flavones, hentri acontane, pentatria contane, alfa and beta chlorophylls, phytin, resins, $\mathrm{d}$ - quercitol, tartaric acid, formic acid, lupeol, beta amyrin. This plant leaves effects as a hypoglycaemic effect are:

- It is increase secretion of insulin

- It promotes regeneration of islet cells

- It increases utilization of glucose

- It causes inhibition of glucose absorption from intestine $[24,25]$.

The plant flowers, leaves act as an antidiabetes mellitus and similar hypo/hyperglycemic conditions.

\section{Acids:}

All acids have in their pathogeneses a common symptom clearly marked. It is debility. Not only the patient who has slight or transitory diabetes but also the patient who suffers from important, durable and irremediable glycosuria. Morbid states are accompanied by diabetes, when it persists for a long time say for years. These are dyspepsias.

Acetic acidum: This is indicate great weakness, frequent swooning. Persons with flaccid fibres, loose muscles, pale leady colour of the skin, emaciation. Great thirst, tendency to oedema, frequent dyspeptic troubles, burning in the stomach, hyperacidity, gastric fermentation, salivation, buring pain in the stomach followed by the sensation of coldness of the skin and cold sweats on forehead.

Boric Acidum: It suits to diabetics with urinary troubles, dry cracked tongue, red. Gushes of heat during menopause, tendency to the oedema of the face, specially of the eyelids, sensation of intense coldness and cold salivation.

Lactic acidum: Diabetes with marked Polyuria. The remedy is interesting to study in its action, because $\mathrm{i}$ know that the muscles which while working produces lactic acid while they become tired, rather sarcolactic acid which does not differ from real lactic acid but by its polarimetric roation. Thus the game which is 
chased has the muscles very stiff because of the formation of sarcolactic acid. This fact denotes in Homoeoapthy great muscular weakness.

Lactic acid will be useful in some cases of dyspeptic conditions with copious salivation, nausea, better by eating, acid eructations or still in rheumatising condition with weakness and trembling by the lease effort.

Fluoricum acidum: Diabetes with circulatory troubles of the lower extremities, atony of venous blood vessels and of capillaries, tendency to ulcers. Diabetes associated with syphilis, old, acquired or hereditary.

\section{Metals:}

Generally the metals, especially the heavy metals are used in Homoeopathy very often for the treatment of prolonged chronic disease, accompanied by deep troubles and definite lesions which is very often the case in diabetes.

Aurum metallicum: Like fluoric acid suits to cases of diabetes associated with old acquired and hereditary syphilis. Exaggerated appetite and thirst, tendency to paralysis. Diplagia, hemianopia. Tendency to general and partial paralysis with hypertension.

Uranium nitricum: Excessive thirst, voracious appetite, abdominal distension, Polyuria, sexual weakness, liver is attacked and goes towards degeneration and hypertrophic cirrhosis after a first phase of congestion.

Cuprum arsenicum: It is to be preferred to cuprum metallicum in some cases of paralysis with muscular atrophy, arteriosclerosis, sclerous degeneration of the marrow.

Minerals: These are used generally as ground remedies or as remedies of morbid temperament.

Arsenicum album: The intoxication by arsenic is at the same time so intense, so varied and so deep that it may be called one of our great polychrests. In diabetes it is indicated by weakness and prostration if the latter alternates or co exists with restlessness, the periodicity of troubles.

Silicea : Its suppurative tendency, silicea will very often be indicated with hepar sulphur in diabetes who have panaries and furuncles. In all these cases all the remedies of suppuration of septicaemia, may be indicated. Silicea in the acute cases, will stop menacing suppuration, the latter on the contrary may sometimes favour the suppuration dangerously. Silicea sutis to chronic suppuration which are weakening and with fistula.

\section{Iodium:}

It suits to diabetics with denutrition, voracious appetite and great thirst, great debility, sweats by the least effort. Suits also to diabetics who becomes tubercular, rapid emaciation. The hunger is such that the patients are anxious while waiting for the meals.

\section{Biochemic or organotherapic remedies:}

Biochemic remedies we mean some products exist naturally in the human organism. This branch of Homoeopathy is still less known. It is related to organotherapy and seems to be very important in future, if we consider them according to the good results obtained as for example with adrenalin in some cases of arterial hypertension.

Insulin: It is evident that we should not ignore insulin and we should use it in homoeopathy according to the habitual method. But we should avoid to give it very frequently and we should not use it in gross doses because of its dangers. It should be prescribed in grave cases of diabetes in lean and thin consumptive patients and also in coma and in the menace of coma as a remedy of urgency.

\section{CONCLUSION:}

Homoeopathic medicines are based up on Similia, Similbus Curentur, "likes cure likes". All homoeopathy medicines will prescribe on bases of totality of symptoms. Homoeopathic medicines are safe, economic and human friendly.

\section{REFERENCE:}

1. International Diabetes Federation. IDF diabetes atlas. 5th ed. Brussels, Belgium: International Diabetes Federation, 2012.

2. Leite, R.S., Marlow, N.M., Fernandes, J.K. Oral health and type 2 diabetes. Am. J. Med. Sci. 2013; 345(4): 271-273.

3. Forbes, J.M., and Cooper, M.E. Mechanisms of diabetic complications. Physiol. Rev. 2013; 93: 137-188. 
4. Shapiro, K. and Gong, W. C. Natural products used for diabetes. J. Am. Pharm. Assoc. 2002; 42(2): 217-226.

5. Gobert C. P. and Duncan, A. M. Consumption, perceptions and knowledge of soy among adults with type 2 diabetes. J. Am. Coll. Nutr. 2009; 28(2): 203-218.

6. Jiang, C. S., Liang, L. F. and Guo, Y.W. Natural products possessing protein tyrosine phosphatase 1B (PTP1B) inhibitory activity found in the last decades. Acta Pharmacol. Sinica. 2012; 33(10): 1217-1245.

7. Upadhayay. V. P. and Pandey,K., In Ayurvedic approach to diabetes mellitus and its management by indigenous resources. Diabetes Mellitus in Developing Countries, Interprint, New Delhi, 1984, 375-377.

8. The encyclopedia of fruit \& nuts, By Jules Janick, Robert E. Paull, p. 552.

9. Chen, Jie \& Craven, Lyn A., "Syzygium", in Wu, Zhengyi; Raven, Peter H. \& Hong, Deyuan, Flora of China (online), eFloras.org, retrieved 2015-0813.

10. Ross. I. A., Medicinal Plants of the World, $2^{\text {nd }}$ edition, Vol-1, Humana Press, Totowa,New Jersey, 2003, 445-451.

11. Siva rami redddy E. Syzygium cumini. A review of its phytochemical and homoeopathic uses.ISCA.2017; 5(4): 1-4.

12. Cefalu WT, Ye J,Wang ZQ, . Efficacy of dietary supplementation withbotanicals on carbohydrate metabolism in humans. endocrine, Metabolic \& Immune disorders Drug Targets 2008 ; 8:78-81.

13. Leung L, Birtwhistle R, Kotecha J, Hannah S Cuthbertson S. Anti diabetic and hypoglycaemic effects of Momordica charantia (bitter melon): A mini review, British Journal of Nutrition, (2009).

14. Modak M,Dixit P,Londhe J,Ghaskadbi S, . Indian herbs and herbal druga used for the treatment of diabetes. J. Clin. Biochemistry Nutri , 2007; 40: 163- 173.

15. Nahas R, Moher . Complementary and alternative medicine for the treatment of type 2 diabetes. Can Fam Physician 2009; 55:591- 596.
16. Basch E, Gabardi S, Ulbaricht C. Bitter melon (Momordica charantia): A review of efficacy and safety. Am J. Health Syst Pharm, 2003; 60: 356359.

17. Central Council of Research in Homoeopathy. Effects of Momordica charantia in Alloxanised Hyperglycemic Rabbits - An Experimental Approach. CCRH Quarterly Bulletin, 2004, 26(2): 3-7

18. Singh J.Cumming, E.Manmohan, G.Kalasz, H.Adeghate, E .The Open Medicinal Chemistry Journal 2011; 59:70-77. Deokate UA, Khadabadi SS, Pharmacology and phytochemistry of Coccinia indica, Journal of Pharmacognosy and Phytotherapy, 3, 2011, 155-159.

19. Prajapati ND, Purohit SS, Sharma VK, Kumar T, Handbook of Medicinal Plants, Agrabios, India, 2003.

20. Anupam Jamwal, SureshKumar, A review of Cephalandra indica Naud, Indian Journal of research in pharmacy and Biotechnology,3, 2015,256-280.

21. Hussain A, Wahab S, Zarin I, Hussain S. Antibacterial activity of the leaves of Coccinia indica (W. and A) W of India. Adv Biol Res., 2010; 4(5): 241-248.

22. K.D.Mwambete; The in vitro Antimicrobial Activity of Fruit and Leaf Crude Extracts ofMomordica Charantia: ATanzaniaMedicinal Plant., Muhimbili University of Health \&Allied Sciences, School of Pharmacy, Department of Pharmaceutical Microbiology, P.O. Box 65013,Dar es Salaam, Tanzania (2013).

23. Boericke W. Pocket manual of Homoeopathic Materia Medica and Repertory. B. Jain Publishers Ltd. 2000:1058.

24. Nakamura y, Tsumura Y, Tonogai Y, Shibata T. Nakamura y, Tsumura Y, Tonogai Y, Shibata T. Fecal steroid excretion is increased in rats by oral administration of gymnemic acids contained in Gymnema sylvestre leaves. J Nutr. 1999; 129:1214-1222.

25. Gulab S, Thakur, Rohit Sharma, Bhagwan. Gymnema Sylvestre: An alternative therapeutic agent for management of diabetes. J App Pha Sc.2012;2(12): 001-006. 